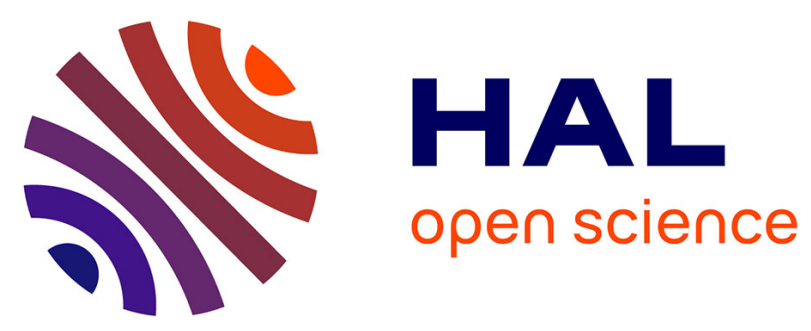

\title{
Interaction between ring shaped permanent magnets with symbolic gradients: application to magnetic bearing system optimization
}

Benoît Delinchant, Frédéric Wurtz, Jean-Paul Yonnet, Jean-Louis Coulomb

\section{- To cite this version:}

Benoît Delinchant, Frédéric Wurtz, Jean-Paul Yonnet, Jean-Louis Coulomb. Interaction between ring shaped permanent magnets with symbolic gradients: application to magnetic bearing system optimization. IEEE Transactions on Magnetics, 2011, 47 (5), pp.1418-1421. hal-00596904

\section{HAL Id: hal-00596904 https://hal.science/hal-00596904}

Submitted on 30 May 2011

HAL is a multi-disciplinary open access archive for the deposit and dissemination of scientific research documents, whether they are published or not. The documents may come from teaching and research institutions in France or abroad, or from public or private research centers.
L'archive ouverte pluridisciplinaire HAL, est destinée au dépôt et à la diffusion de documents scientifiques de niveau recherche, publiés ou non, émanant des établissements d'enseignement et de recherche français ou étrangers, des laboratoires publics ou privés. 


\title{
Interaction Between Ring-Shaped Permanent Magnets With Symbolic Gradients: Application to Magnetic Bearing System Optimization
}

\author{
B. Delinchant, F. Wurtz, J.-P. Yonnet, and J.-L. Coulomb \\ Grenoble Electrical Engineering lab, BP 46, 38402 Saint-Martin d'Hères, France
}

\begin{abstract}
This paper presents a semi-analytical calculation of the interaction between magnetic bodies with ring shapes. It leads to fast and accurate evaluation of forces and torques but also to the symbolic expression of their gradients. Our method can be used to compute partial derivatives to address optimization needs. It has been implemented into an available software environment in order to be automatically available for end users. Efficient optimization can be done to size magnetic bearing systems.
\end{abstract}

Index Terms-Elliptic integrals, magnetostatic analytical modeling, optimization, ring-shaped magnet.

\section{INTRODUCTION}

\section{A. Magnet Bearing Systems}

A PPLICATIONS which use magnetic devices like magnetic bearings and couplings, strong field generation, or micro actuators and sensors, can be modeled by analytical expressions. Ring-shaped permanent magnets are specially used in magnetic bearings like Fig. 1, and are used in several systems:

- flywheels: to store rotational energy;

- centrifuge: to collect Uranium-235;

- turbopump: to obtain and maintain high vacuum.

\section{B. Magnetic Interactions Modeling}

The modeling of cylindrical magnets can be based on Coulombian method with equivalent surface charges $\sigma_{s}=\vec{J} \cdot \vec{n}$ where "n" defines the unit vector normal to surface and " $\mathrm{J}$ " the magnetic polarization. Volume charges appear for radial polarization.

By symbolic integration of (1) in polar coordinates, axial and radial components are expressed with elliptic integral of the three kinds [2]-[4]

$$
\vec{H}_{P}=\frac{\sigma}{4 \pi \mu_{0}} \iint_{s} \cdot \frac{\vec{r}-\overrightarrow{r^{\prime}}}{\left|\vec{r}-\overrightarrow{r^{\prime}}\right|^{3}} d S .
$$

Forces can then be found by numerical integration of these fields by an equivalent charge (surface $\sigma_{S}$ and volume $\sigma_{V}$ ) method applied on the other magnets

$$
\vec{F}=\iint_{s} \sigma_{s} \cdot \overrightarrow{H_{e x t}} d s+\iiint_{v} \sigma_{v} \cdot \overrightarrow{H_{e x t}} d v .
$$

\section{Sensitivity Calculation to Perform Optimization}

More and more optimization procedures are performed over analytical model to obtain constrains satisfaction and optimal

Manuscript received May 31, 2010; revised October 27, 2010; accepted November 04, 2010. Date of current version April 22, 2011. Corresponding author: B. Delinchant (e-mail: benoit.delinchant@G2Elab.grenoble-inp.fr).

Color versions of one or more of the figures in this paper are available online at http://ieeexplore.ieee.org.

Digital Object Identifier 10.1109/TMAG.2010.2091718

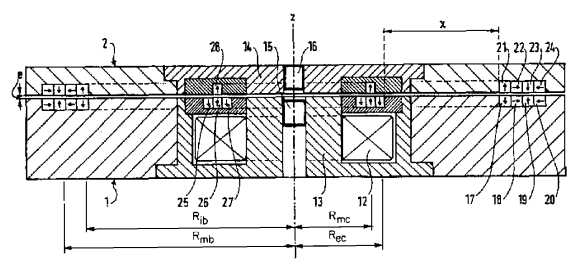

Fig. 1. Magnetic bearing patent [1].

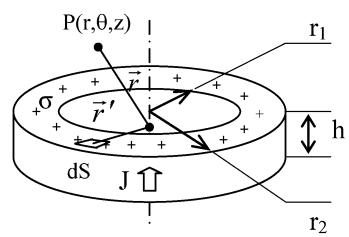

Fig. 2. Cylindrical magnet equivalent surface charges modeling.

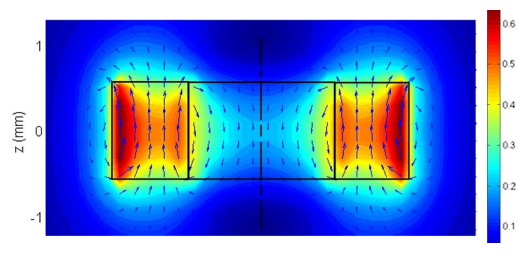

Fig. 3. $|\mathrm{B}(\mathrm{x}, \mathrm{z})|$ and $\mathrm{B}(\mathrm{x}, \mathrm{z})$ vectors for $\mathrm{y}=0, \mathrm{Mz}=1 \mathrm{~T}$.

design, even with the availability of numerical model. In our case, partial derivatives of force can be expressed using the general ((3)) $(a, b, c \in \Re)$

$$
\begin{array}{r}
\frac{\partial}{\partial c} \int_{a(c)}^{b(c)} f(c, x) \cdot d x=\int_{a(c)}^{b(c)} \frac{\partial f(c, x)}{\partial c} \cdot d x+\frac{\partial b(c)}{\partial c} \cdot f(c, b(c)) \\
-\frac{\partial a(c)}{\partial c} \cdot f(c, a(c)) .
\end{array}
$$

Each term of (2) derivation is available expected partial derivatives of the elliptic evaluation of $\mathrm{H}_{\text {ext }}$.

The aim of the paper is to present symbolic approach to compute magnetic forces and torques sensitivity, and to present automatic tool to combine partial derivatives.

\section{ELLIPTIC INTEGRALS}

\section{A. Definitions}

Elliptic integrals appear during the integration of magnetic field in polar coordinates. There are of three kinds, given here 
((4), (5), (6)) in Legendre's notation for incomplete form (the complete form is for $\Phi=\pi / 2$ )

$$
\begin{aligned}
\mathrm{F}(\mathrm{k}, \phi) & =\int_{0}^{\phi} \frac{1}{\sqrt{1-\mathrm{k}^{2} \cdot \sin (\theta)}} \mathrm{d} \theta \quad \text { "first kind" } \\
\mathrm{E}(\mathrm{k}, \phi) & =\int_{0}^{\phi} \sqrt{1-\mathrm{k}^{2} \cdot \sin (\theta)^{2}} \mathrm{~d} \theta \quad \text { "second kind" } \\
\Pi(\mathrm{k}, \mathrm{n}, \phi) & =\int_{0}^{\phi} \frac{1}{\left(1+\mathrm{n} \cdot \sin (\theta)^{2}\right) \cdot \sqrt{1-\mathrm{k}^{2} \cdot \sin (\theta)^{2}}} \mathrm{~d} \theta
\end{aligned}
$$

The definition can be lightly different for several authors or mathematical environments ( $m=k^{2}$, or " $n$ " is preceded by a minus sign).

\section{B. Numerical Evaluation}

There are several algorithms for the computation of complete or incomplete elliptic integrals, mainly based on arithmetic-geometric mean (AGM) algorithm. They can differ for the range of parameter " $\Phi$," "k," and "n" [6]. For example, the algorithm given in [5] for " $\Pi$ " will not work in the modeling of cylindrical magnets where " $k$ " range is out of $[0,1]$. We are using a performing algorithm founded by Carlson [7] and available in Numerical Recipes [8].

We have compared Elliptic implementation with the one given in (7) where symbolic integration is done as far as possible (1D numerical integration remains). Computation is about 200 times faster, and has less singularity. Fig. 3 presents induction values obtained in few seconds and plotted in Matlab shown in

$$
H_{z}=\frac{\sigma_{s}}{4 \pi \mu_{0}} \cdot \int_{\theta_{0}}^{\theta_{1}} \sum_{i=0}^{1} \cdot \sum_{j=0}^{1}(-1)^{i+j}\left[\left(z-(-1)^{j} c\right) g(\theta)\right] d \theta
$$

with

$$
g(\theta)=\frac{-\left(z-(-1)^{j} c\right)^{2}-\left(x^{2}+y^{2}\right)+r_{i}(x \cos (\theta)+y \sin (\theta))}{\left((x \sin (\theta)-y \cos (\theta))^{2}+\left(z-(-1)^{j} c\right)^{2}\right) \phi(x, y, z, i, j, \theta, c)} \text {. }
$$

\section{Symbolic Sensitivity}

For each elliptic function, a partial derivative regarding " $\Phi$ " parameter can be obtained

$$
\begin{aligned}
\frac{\mathrm{dF}(\mathrm{k}, \phi)}{\mathrm{d} \phi} & =\frac{1}{\sqrt{1-\mathrm{k}^{2} \cdot \sin (\phi)^{2}}} \\
\frac{\mathrm{dE}(\mathrm{k}, \phi)}{\mathrm{d} \phi} & =\sqrt{1-\mathrm{k}^{2} \cdot \sin (\phi)^{2}} \\
\frac{\mathrm{d} \Pi(\mathrm{k}, \mathrm{n}, \phi)}{\mathrm{d} \phi} & =\frac{1}{\left(1+\mathrm{n} \cdot \sin (\phi)^{2}\right) \cdot \sqrt{1-\mathrm{k}^{2} \cdot \sin (\phi)^{2}}} .
\end{aligned}
$$

Another partial derivative can be computed regarding " $\mathrm{k}$ " $\mathrm{pa}$ rameter ((12), (13), (14)). The demonstration ((11)) is done for second kind function $\mathrm{E}(\mathrm{k}, \Phi)$

$$
\begin{aligned}
\frac{\mathrm{d}}{\mathrm{dk}} & \sqrt{1-\mathrm{k}^{2} \cdot \sin (\theta)^{2}} \\
& =\frac{-\mathrm{k} \cdot \sin (\theta)^{2}}{\sqrt{1-\mathrm{k}^{2} \cdot \sin (\theta)^{2}}}=\frac{1}{\mathrm{k}} \cdot \frac{1-\mathrm{k}^{2} \cdot \sin (\theta)^{2}-1}{\sqrt{1-\mathrm{k}^{2} \cdot \sin (\theta)^{2}}} \\
& =\frac{1}{\mathrm{k}} \cdot\left(\sqrt{1-\mathrm{k}^{2} \cdot \sin (\theta)^{2}}-\frac{1}{\sqrt{1-\mathrm{k}^{2} \cdot \sin (\theta)^{2}}}\right) .
\end{aligned}
$$

Then,

$$
\frac{\mathrm{d}}{\mathrm{dk}} \mathrm{E}=\frac{1}{\mathrm{k}} \cdot(\mathrm{E}-\mathrm{F})
$$

The same can be done for "F" and " $\Pi$ "

$$
\begin{aligned}
\frac{\mathrm{d}}{\mathrm{dk}} \mathrm{F}= & \frac{1}{\mathrm{k}} \cdot\left(\frac{\mathrm{E}}{1-\mathrm{k}^{2}}-\mathrm{F}\right) \\
& +\frac{\mathrm{k} \cdot \sin (2 \cdot \phi)}{2 \cdot\left(\mathrm{k}^{2}-1\right) \cdot \sqrt{1-\mathrm{k}^{2} \cdot \sin (\phi)^{2}}} \\
\frac{\mathrm{d}}{\mathrm{dk}}= & \frac{-\mathrm{k}}{\mathrm{k}^{2}+\mathrm{n}} \cdot\left[\frac{\mathrm{E}}{\mathrm{k}^{2}-1}+\Pi\right. \\
& \left.\quad-\frac{\mathrm{k}^{2} \cdot \sin (2 \cdot \phi)}{2 \cdot\left(\mathrm{k}^{2}-1\right) \cdot \sqrt{1-\mathrm{k}^{2} \cdot \sin (\phi)^{2}}}\right] .
\end{aligned}
$$

Last partial derivative for " $\Pi$ " regarding " $\mathrm{n}$ "

$$
\begin{aligned}
& \frac{d}{d n} \Pi=\frac{1}{2 \cdot n(n+1) \cdot\left(k^{2}+n\right)} \cdot\left[n \cdot E-\left(k^{2}+n\right) \cdot F\right. \\
& \left.+\left(k^{2}-n^{2}\right) \cdot \Pi \cdot+\frac{n^{2} \cdot \sqrt{1-k^{2} \cdot \sin (\phi)^{2}} \cdot \sin (2 \cdot \phi)}{2 \cdot(1+n \cdot \sin (\phi))}\right]
\end{aligned}
$$

\section{SOFTWARE IMPLEMENTATION}

\section{A. CADES Framework}

A framework detailed in [9] and available at [10], has been developed for optimization requirements. The modeling language is based on the analytical model description made of algebraic equations and explicitly defined functions. However, this simple description may be limited in electromagnetic, and semi-analytical modeling is also available thanks to numerically computed external functions with analytical model call back possibilities.

1) Semi-Analytical Modeling: A standard interface has been defined to integrate numerical code into CADES Framework called "external functions." Many experiences have been done to compose heterogeneous solvers like FLUX2D, SABER, MATLAB,$\ldots$ using this functionality. In our study two numerical code are required, the Elliptic functions library to compute magnetic fields and a numerical integration routine to evaluate forces. The challenge in modeling for optimization is to evaluate the model sensitivity.

2) Global Sensitivity Modeling: The external function interface can also provide a Jacobian matrix for each numerical routine. First of all, partial derivative of magnetic fields is given by partial derivatives of elliptic functions composed with standard functions depending on the magnetic field formulas. Then, partial derivative of forces is expressed from integral derivation and 


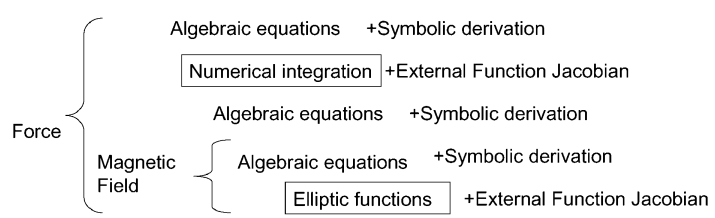

Fig. 4. Global sensitivity composition.

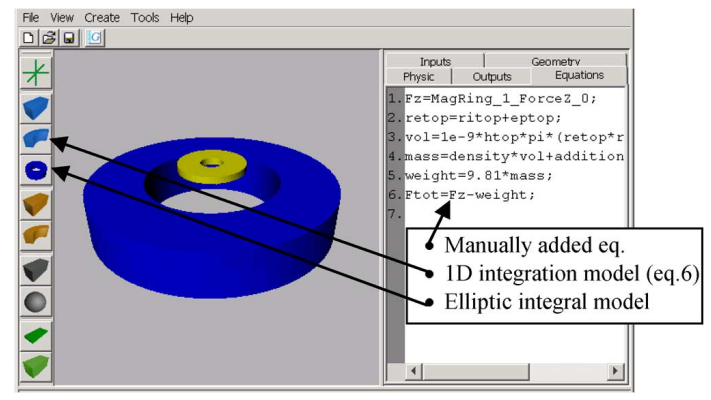

Fig. 5. MacMMems: semi-analytical modeling of magnetic components.

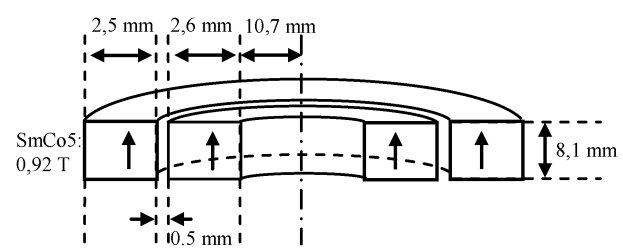

Fig. 6. Simple magnetic bearing geometry description.

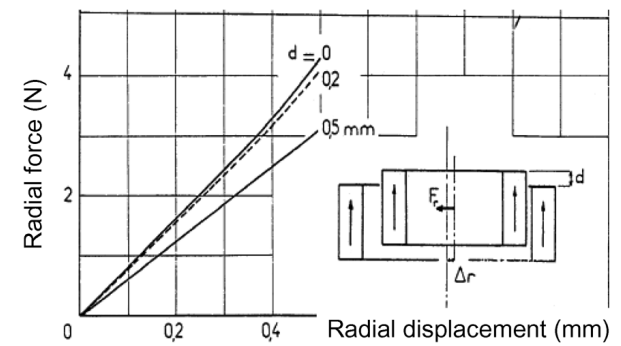

Fig. 7. Radial force vs. radial displacement for several axial positions.

field derivatives (see Fig. 4). The composition is done automatically in the CADES Framework to produce the global Jacobian matrix.

P. Enciu describes CADES semi-analytical modelling and Jacobian compositions with A.D. (automatic differentiation) technique. Compared with our symbolic approach, the A.D. technique is general but slower during computation [11].

In order to reach high performances, CADES framework is also able to select a path in the partial derivative composition tree. Indeed, during optimization only objective function and constraints have to be derivate regarding design parameters.

\section{B. MacMMems: Macro Modeler for Magnetic Mems}

Software has been developed in order to capitalize analytical and semi-analytical models for simple shape magnetic bodies (magnets, coils, diamagnetic and analytical ferromagnetic) and make them interact (forces and torques computation). Equations can also easily be added.

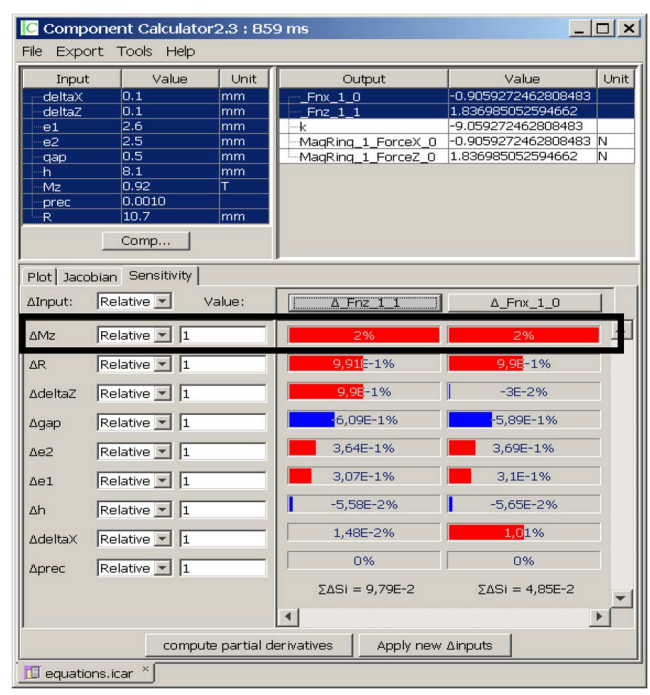

Fig. 8. Sensitivity calculation ( $859 \mathrm{~ms})$ of axial (Fnz) and radial (Fnx) regarding all parameters, sorted by Fnz most influenced parameters.

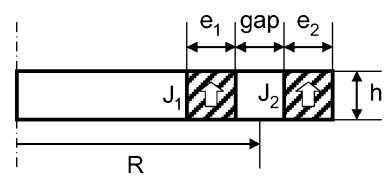

$\mathrm{e}_{1}=\mathrm{e}_{2}=5 \mathrm{~mm}$ gap $=1 \mathrm{~mm}$ $\mathrm{J}_{1}=\mathrm{J}_{2}=1.25 \mathrm{~T}$

Fig. 9. Magnets parameters to be designed.

When system description is done, MacMMems generates equations, which are passed through CADES to produce an autonomous computation code (software component) with symbolic derivatives.

\section{EXAmPle OF ElEMENTARY MAGNETIC BEARING}

\section{A. Geometry Description}

Fig. 6 presents the geometry of a simple magnetic bearing based on axially magnetized ring shaped magnets.

\section{B. Comparison With Measures}

Fig. 7 presents radial force measurements [12], [13]. Axial and radial forces have been retrieved using the modeling formulas.

\section{Sensitivity Analysis}

Fig. 8 presents CADES calculator on this model and details sensitivity values. These sensitivities are computed very quickly using model Jacobian matrix and are very accurate to evaluate stiffness. The most influencing parameter is magnetization value $(\mathrm{Mz})$ which increase Fnz and Fnx of $2 \%$ when it increase of $1 \%$.

\section{STIFFNESS OPTIMIZATION}

\section{A. Stiffness Regarding Magnets Height}

Radial stiffness $(\operatorname{Fr}(\Delta \mathrm{r}) / \Delta \mathrm{r})$ can be optimized regarding geometrical and physical parameters. In our basic example, only height parameter ("h" in Fig. 9) can reach an optimum.

Fig. 10 shows that an optimal value of height exists to obtain a maximal value of the stiffness. 


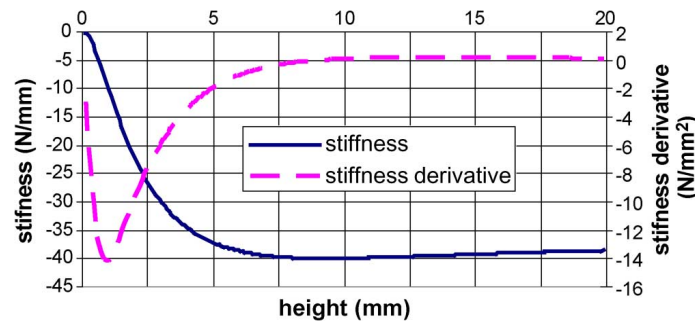

Fig. 10. Radial stiffness and its derivative regarding magnets height.

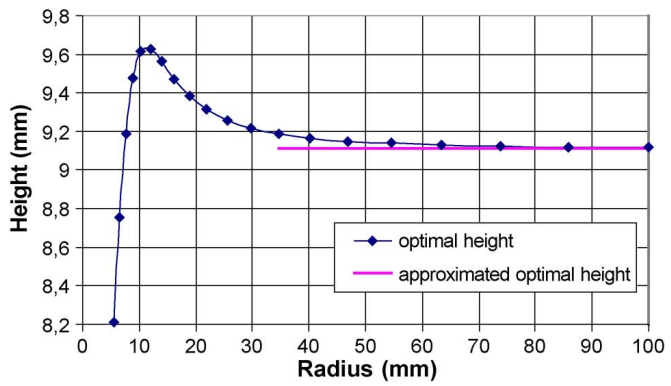

Fig. 11. Optimal height values regarding magnet radius.
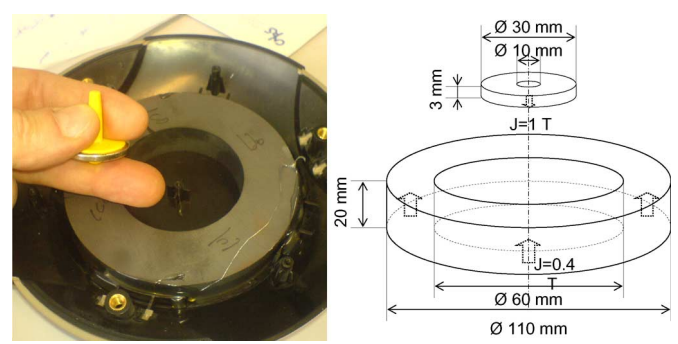

Fig. 12. Levitron photography and geometrical parameterization.

\section{B. Optimal Height Depending on Radius}

In the approximation of infinite radius, and for geometry with $\mathrm{e}_{\mathrm{i}}=5$.gap (see parameters name in Fig. 9), it has been proved that optimal height $=\sqrt{83}=9.11 \mathrm{~mm}$ [12], [13]. This result has been obtained by a model where rings are approximated by $2 \mathrm{D}$ rectangular section magnets. With our new model and its derivatives it is possible to find more accurate optimization results for low radius.

Fig. 11 has been obtained by successive optimization using quasi-Newton algorithm (SQP: sequential quadratic programming) allowing finding optimal height very quickly (all points are obtained in less than 15 seconds) due to noiseless model derivatives.

\section{APPLICATION TO LEVITRON IDENTIFICATION}

Levitron is based on axial magnetized cylindrical magnets, a fixed one and a smaller mobile one on the top. Magnetizations are opposed, creating an unstable repulsing force which is stabilized by gyroscopic effect.

We have measured such a system (geometry and magnetic induction values in several points) to identify magnets magnetization. A least square procedure has been done with our model using sensitivities to ensure quick and accurate identification convergence.
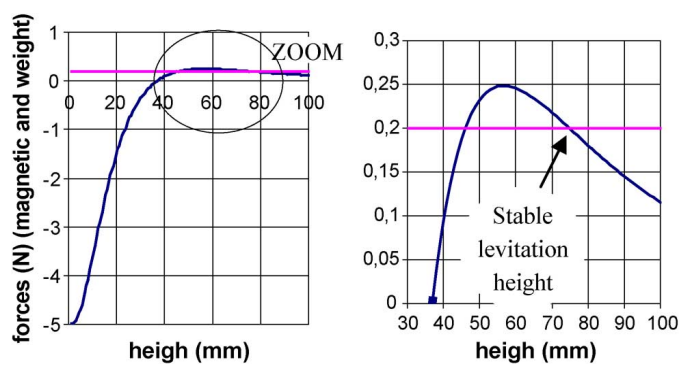

Fig. 13. Levitron magnetic force and weight giving levitation height.

Simulated levitation height is founded at $7.5 \mathrm{~cm}$ Fig. 13 (intersection with weight), which correspond well to our measurements.

\section{CONCLUSIONS}

Partial derivatives of elliptic functions are given in order to be composed and to produce the partial derivative of magnetic field produced by circular shaped magnets. Using integration symbolic derivation, partial derivatives of forces are also available. This modeling technique has been implemented in our modeling and optimization framework and has shown very good performances regarding other methods. This original and generic approach has been demonstrated in three cases:

- Magnetic bearing sensitivity study;

- Magnetic bearing stiffness optimization:

- Levitron identification and simulation.

Using symbolic gradients and dedicated tools to generate it automatically, brings significant improves regarding classical method (manual analytical modeling, or numerical with generic software).

\section{REFERENCES}

[1] J. Delamare, J.-P. Yonnet, and E. Rulliere, "A compact magnetic suspension with only one axis control," IEEE Trans. Magn., vol. 30, no. 6, pp. 4746-4748, Nov. 1994.

[2] E. P. Furlani, Permanent Magnet and Electromechanical Devices. New York: Academic Press, 2001.

[3] R. Ravaud et al., "Analytical calculation of the magnetic field created by permanent-magnet rings," IEEE Tran. Magn., vol. 44, no. 8, pp. 1982-1989, Aug. 2008.

[4] S. I. Babic and C. Akyel, "Improvement in the analytical calculation of the magnetic field produced by permanent magnet rings," Progr. Electromagn. Res. C, vol. 5, pp. 71-82, 2008.

[5] M. Lang, "Fast calculation method for the forces and stiffnesses of permanent-magnet bearings," in Proc. 8th Int. Symp. on Magnetic Bearing, Mito, Japan, 2002, pp. 533-538.

[6] L. Urankar, P. Henninger, and F. S. Nestel, "Compact extended algorithms for elliptic integrals in electromagnetic field and potential computations. II. Elliptic integral of third kind with extended integration range," IEEE Trans. Magn., vol. 30, no. 3, pp. 1236-1241, May 1994.

[7] B. C. Carlson, "Computing elliptic integrals by duplication," Numer. Math., vol. 33, no. 1, 1979.

[8] Numerical Recipes [Online]. Available: www.nr.com

[9] B. Delinchant et al., "An optimizer using the software component paradigm for the optimization of engineering systems," COMPEL, vol. 26, no. 2, pp. 368-379, 2007.

[10] [Online]. Available: http://forge-mage.g2elab.grenoble-inp.fr/project/ cadesframework/download

[11] P. Enciu, F. Wurtz, L. Gerbaud, and B. Delinchant, "Automatic differentiation for electromagnetic models used in optimization," COMPEL, vol. 28, no. 5, pp. 1313-1326, 2009, 0332-1649.

[12] J. P. Yonnet, "Etude des paliers magnétiques passifs," Ph.D. dissertation, Thèse de Docteur d'Etat, Grenoble, Juillet 2, 1980.

[13] J.-P. Yonnet, "Analytical calculation of magnetic bearings," in Proc. 5th Int. Workshop on RE-CO PM and Their Applications, Roanoke, VA, Jun. 7-10, 1981, pp. 199-216. 